\title{
19
}

\section{Evoking the Imagination as a Strategy of Influence}

\author{
Petia K. Petrova \\ Dartmouth College \\ Robert B. Cialdini
}

Arizona State University

The human race is governed by its imagination.

\section{Napoleon Bonaparte}

Browse the pages of any popular magazine, and you will be invited to imagine yourself experiencing various products. To evoke consumption imagery, advertisers often use appeals such as "imagine yourself in a Mercury," "find yourself here," or "imagine your perfect home." 3D advertising and virtual realities encourage consumers to interact with the product and visualize the consumption experience (Griffth \& Chen, 2004; Grigirivici, 2003; Li, Daugherty, \& Biocca, 2002; Schlosser, 2003; Sheridan, 1992). Imagery is a central component of narrative stories (Green \& Brock, 2000; Mandel, Petrova, \& Cialdini, 2006), drama ads (Deighton, Romer, \& McQueen, 1989; Stern, 1994), slice-of-life ads (Mick, 1987), and transformational ads (Puto \& Wells, 1984). Consumer researchers define imagery as a process by which sensory information is represented in working memory (MacInnis \& Price, 1987). Imagery has been distinguished from discursive, analytical processing of information such as verbal encoding, cognitive responding, counterarguing, and formulation of choice rules. Whereas discursive processing involves abstract symbols, words, and numbers (MacInnis \& Price, 1987), imagery involves encoding in the form of nonverbal concrete sensory representations (Childers, Houston, \& Heckler, 1985; Epstein, 1994).

The existing evidence suggests that imagery can have powerful effects on consumers' behavior. It has been shown to enhance memory (Lord, 1980; Slee, 1978; Swann \& Miller, 1982), even to create false memories (Garry \& Polaschek, 2000; Gonzalves et al., 2004; Schlosser, 2006), and to increase the perceived likelihood of an event (Carroll, 1978; Cialdini, 2001; Gregory, Cialdini, \& Carpenter, 1982; Sherman, Cialdini, Schwartzman, \& Reynolds, 1985). For example, imagining a political candidate winning the election can increase the perceived likelihood of the candidate's victory (Carroll, 1978), and imagining winning the lottery can increase the perceived chance of winning (Gregory et al., 1982). Imagery has also been demonstrated to increase the intentions to perform a behavior (Anderson, 1983; Cialdini, 2001; Gregory et al., 1982). Imagining taking a trip, starting a new job, or donating blood increased an individual's intentions to engage in these activities (Anderson, 1983). 
Of course, of specific interest to consumer researchers are the effects of product imagery. Research in this direction reveals that instructing individuals to use their imagination while processing the product information (Keller \& Block, 1997; Keller \& McGill, 1994; Krishnamurthy \& Sujan, 1999; McGill \& Anand, 1989) or incorporating imagery appeals in an ad (Babin \& Burns, 1997; Bone \& Ellen, 1992; Escalas, 2004) can enhance product evaluations and the likelihood of purchasing the product. For example, in one of the first studies on the effects of imagination in a consumer context (Gregory et al., 1982), half of the residents in a neighborhood were given information about the features of a cable service. The other half of the residents were asked to imagine themselves utilizing the features of the cable service. Several weeks later, representatives from the cable company solicited these residents' orders for cable service. The results revealed that $19.5 \%$ of the residents who had only heard the features of the product subscribed to the service. However, among those that imagined having the cable TV service, the subscription rate was $47.4 \%$. Simply asking consumers to imagine having the product doubled the sales rate.

Given the evidence for the effects of imagery on consumers' judgments and behavior, it is important to understand the mechanisms through which such effects occur. Researchers have suggested several mechanisms, yet how imagery changes consumers' preferences and behavior is not fully understood. Hoping to spur more research in this direction, we review the existing evidence for the processes underlying the effects of imagery and suggest unexplored possibilities. We also review variables moderating these effects and outline conditions under which asking consumers to imagine their experience with the product can be particularly effective or, alternatively, can decrease the likelihood of purchasing the product. Our goal is twofold: to provide an integrative view of the different approaches toward the use of imagery as a strategy of influence, and to inspire new ideas in this fascinating domain of consumer psychology.

\section{PROCESSES UNDERLYING THE EFFECTS OF IMAGERY}

Visualizing is a way of knowing: it is a mode of generating knowledge... . How we see determines what we see; and how we see is embodied in our mental images. By virtue of their condensing impulse, images have a kind of power that abstract ideas can never have.

Mervyn Nicholson, 13 Ways of Looking at Images

\section{Traditional Approaches}

Traditional approaches in persuasion research have focused on processes such as affect, consideration of arguments, and recall. Such approaches have been applied to the effects of imagery as well. For example, studies suggest that because of the affective responses it evokes, imagery can enhance product evaluations (Bolls, 2002; Goossens, 1994, 2000; Mani \& MacInnis, 2001; Oliver, Thomas, \& Mitchell, 1993; Strack, Schwarz, \& Gschneidinger, 1985). Research also reveals that information processed using imagery is stored in both a sensory code and a semantic code; thus imagery has multiple linkages in memory (Childers \& Houston, 1984; Kieras, 1978) and is more easily retrieved than information stored in a semantic code only (Houston, Childers, \& Heckler, 1987; Pavio, 1971). Given the role of information accessibility, it has also been suggested that vivid information or instructions to imagine the product are likely to influence product preferences by increasing the accessibility of favorable product-related information (Kisielius \& Sternthal, 1984, 1986). This proposition, known as the availability-valence hypothesis, further suggests that because imagery can increase cognitive elaboration, it can increase or decrease product preferences according to the valence of the product information made accessible. That is, imagery can increase the 
accessibility of not only favorable but also unfavorable product information. In such cases, asking consumers to imagine the product experience can decrease product preferences.

Despite the evidence in support of these processes, more recent research suggests that there are additional processes taking place when consumers imagine the product experience. For example, Mani and MacInnis (2001) and Escalas (2004) reported that imagining the consumption experience influenced consumers' affective responses. In both studies, however, imagery had a positive effect on product preferences even when controlling for affect, suggesting that affect alone cannot account for the positive effects of the imagery on product evaluations. Furthermore, positive affect would not account for the effects of imagery on estimates of the likelihood of negative events such as being arrested for armed robbery (Gregory et al., 1982) or the effects of imagery on the likelihood of performing behaviors evoking negative affect (e.g., blood donation; Anderson, 1983).

Similarly, imagery appeals may engage processes that are different from those evoked by simply presenting individuals with a pictorial product depiction. A recent set of studies revealed that, consistent with the availability-valence hypothesis, increasing the vividness of the product depiction resulted in a greater number of product-relevant thoughts and greater recall of the product information (Petrova \& Cialdini, 2005). However, these effects were not observed with regard to imagery appeals. In fact, instructing participants to process the information using their imagination decreased product-related thoughts, thoughts about specific product attributes, and recall of the product attributes. It has also been demonstrated that imagining the process of using the product can make consumers less sensitive to the strength of the arguments in the ad (Escalas \& Luce, 2003, 2004). Furthermore, the effects of imagery were not mediated by cognitive elaboration (Schlosser, 2003); neither were they moderated by the individuals' dispositional tendency to spontaneously elaborate on information (measured with the Need for Cognition Scale; Cacioppo, Petty, \& Kao, 1984; Green \& Brock, 2000; Schlosser, 2003). According to these findings, imagery may not necessarily increase consideration of the positive and negative features of the product and in some cases may even decrease elaboration on the message arguments. Thus, additional processes may be taking place when consumers imagine their future experience with the product. Recent investigations provide some insight into this possibility.

\section{New Approaches}

Transportation and reduced counterarguing. Contemporary investigations reveal conceptually new processes that may be taking place when consumers engage in imagining the product experience. One such approach stems from findings in the area of narrative transportation. As research on the persuasiveness of narratives reveals, narratives are effective in changing attitudes and beliefs because they transport individuals into a different reality, thus reducing consideration of the positive and negative aspects of the message (Green \& Brock, 2000). The process of transportation has been described as "immersion into a text," and being "lost" in a story (Green \& Brock, 2000, p. 702). "A person engaged in elaboration might be accessing his or her own opinions, previous knowledge, or other thoughts and experiences in order to evaluate the message at hand. Under high elaboration, connections are established to an individual's other schemas and experiences. In contrast, under high transportation, the individual may be distanced temporarily from current and previous schemas and experiences" (p. 702). Imagery may influence product evaluations through a similar mechanism, by transporting consumers into a distant reality and reducing their attention to the favorability of the product information (Escalas, 2004, 2007). When individuals are transported into an imagined world, they may not be motivated to correct for their initial beliefs and expectations, because (a) they may not believe that the imagery had an effect on them, and (b) 
interrupting the imagery to counterargue the information can make the experience less enjoyable. Moreover, because experiencing the imagery is likely to occupy considerable mental resources, individuals may not be able to correct for the initial effects of the imagery on their evaluations. Indeed, recent research suggests that when consumers imagine their experience with the product they are less likely to evaluate the specific product attributes and counterargue the message arguments. For example, argument strength had an impact on the evaluation of the brand when individuals were not asked to imagine their experience with the product, but it did not have an impact when participants engaged in imagery (Escalas, 2004, 2007). Furthermore, when the product was described in a narrative, the inclusion of undesirable product features in the presentation did not affect product evaluations, although this information did undermine evaluations when the product features were presented in a list format (Adaval \& Wyer, 1998). When presented with the narrative description of the product, participants processed the information in a holistic manner and were less likely to draw inferences based on the specific attributes presented in the ad. Such findings are consistent with research examining the effects of imagery on comparative advertising, which demonstrates that advertisements comparing the product to its competitor are effective under analytical processing but not under imagery processing (Thompson \& Hamilton, 2006). Again, these findings suggest that when individuals process product information using their imagination, they are not likely to consider the positive and negative aspects of the presented information, but rather they adopt a more holistic approach, transporting themselves into a fictitious reality.

The imagery accessibility account. Another general area of research that has spurred new investigations into the processes underlying the effects of imagery focuses on consumers' subjective experiences of fluency. A considerable amount of evidence has been accumulated to demonstrate that when forming attitudes, opinions, and judgments, individuals are likely to take into account not only the content of the information with which they are presented, but also the ease with which this information comes to mind (Schwarz, 1998, 2004). For instance, consumers may not necessarily base their product evaluations on the content of the product information with which they are presented; they may base their evaluations instead on the fluency with which they can process this information (Lee \& Labroo, 2004). Furthermore, consumers often base their product preferences not on the number of arguments for purchasing the product that they can generate, but rather on the subjective accessibility of these arguments (Menon \& Raghubir, 2003; Wänke, Bohner, \& Jurkowitsch, 1997).

Based on this approach, in contrast to examining the impact of imagery on consumers' elaboration on the message arguments, the imagery accessibility account focuses on the metacognitive experiences involved in processing product information using imagery. For example, when purchasing a house, consumers may consider how easily they see themselves living in this house. Typically, individuals can easily imagine having products that are suitable for them, that they intend to purchase, or that they desire; therefore, simulating the product experience can be an efficient decision-making strategy. However, the ease with which consumers can imagine themselves with the product can also be influenced by factors irrelevant to their intentions or the merits of the product. For example, when a consumer is deciding on a vacation destination, an image of a vacation in Hawaii might come to mind easily if the individual has previously been provided with imagery-evoking information in brochures or movies. Engaging consumers in product imagery through use of such commercial images of the consumption experience can create readily accessible mental representations of having the product and can increase the ease with which such representations will spring to mind during the decision-making process.

Indeed, research suggests that we tend to use the ease with which we create a mental representation of an event to estimate the likelihood of an event (Sherman et al., 1985). Furthermore, the ease of 
imagery generation has been found to influence not only the perceived likelihood of external events but also product evaluations and purchase intentions (Dahl \& Hoeffler, 2004; Petrova \& Cialdini, 2005; Zhao, Hoeffler, \& Dahl, 2007). Further evidence about the role of imagery accessibility comes from research on the effect of hypothetical questions. As a number of studies in this area have demonstrated, simply asking individuals about the likelihood that they will engage in a behavior could make them actually perform the behavior (Fitzsimons \& Morwitz, 1996; Greenwald, Carnot, Beach, \& Young, 1987; Morwitz, Johnson, \& Schmittlein, 1993). More recent research, however, reveals that this effect is moderated by the ease with which individuals can generate a mental representation of the behavior (Levav \& Fitzsimons, 2006). That is, when asked a hypothetical question about engaging in an activity, individuals spontaneously engage in generating a mental representation of the behavior. Subsequently, they base their intentions to actually perform the behavior on the ease with which a mental representation of the behavior was generated.

These findings suggest that when considering buying a product, individuals may spontaneously attempt to create a mental representation of the product experience. By increasing the accessibility of such representations, imagery appeals can increase the likelihood of purchasing the product.

Imagination-behavior link. A third source of new insight into the effects of imagination comes from research on automatic processes. According to the principle of ideomotor action (James, 1980), the mere act of thinking about a behavior may increase the tendency to engage in that behavior. "We may lay it down for certain that every representation of a movement awakens in some degree the actual movement which is its object" (p. 526). According to James's proposition, activating a representation of the behavior through imagining may increase the likelihood of activating the behavior itself. Contemporary investigations provide findings consistent with this idea. Research on the perception-behavior link suggests that the activation of a perceptual representation may lead to the corresponding behavior (Bargh, Chen, \& Burrows, 1996; Bargh, Gollwitzer, Lee-Chai, Barndollar, \& Trörschel, 2001; Chartrand, Maddux, \& Lakin, 2005; Dijksterhuis \& Van Knippenberg, 1998). Research on ironic processes has also demonstrated that under conditions of limited attentional resources "the mere act of thinking about a behavior causes the behavior, even when the thought involved is meant to help prevent that behavior" (Ansfield \& Wegner, 1996; Wegner, 1994). Because imagery and perception involve similar mental processes (Segal \& Fusella, 1970; Unnava, Agarwal, \& Haugtvedt, 1996), we may expect that-by activating a mental representation of consuming the product-imagery may evoke the actual consumption.

Neurophysiological research also suggests an automatic link between imagination and behavior (Decety, Jeannerod, Germain, \& Pastene, 1991; Jeannerod, 1994, 1997; Paus, Petrides, Evans, \& Myer, 1993; Pulvermuller, Harle, \& Hummel, 2001; Rizzolatti \& Arbib, 1998). A growing body of functional imaging research suggests that imagining an action and the actual production of the action rely upon common neural structures. For example, thinking about a word or gesture leads to the same activation in the anterior cingulated cortex as actually uttering the word or making the gesture (Paus et al., 1993). Similarly, imagining performing actions such as finger and toe flexion and extension and simultaneous horizontal movements of the tongue activated specific somatosensory and motor areas activated during actual motor execution that were also activated during actual performance of these movements (Ehrsson, Geyer, \& Naito, 2003). In another study, participants were asked to perform, imagine, or prepare for specific hand movements while undergoing functional MRI scanning. The results revealed that the actual hand movements activated components of the motor system, including the primary motor and somatosensory cortex, the supplementary motor area (SMA), the thalamus, and the cerebellum. When participants imagined these movements or prepared to perform them, the primary motor cortex, the SMA, and the thalamus were activated (Michelon, 2005). Similar results have been reported with imagining more 
complex actions such as running, rowing, or weightlifting. Imagining such behaviors triggered neurophysiological activities comparable to those generated by actually engaging in these behaviors (Decety et al., 1991; Jeannerod, 1994, 1997).

These findings suggest that imagination and behavior may share the same motor representations, which may be triggered during mental simulation as well as by action preparation, execution, or observation. By activating a picture in front of the mind's eye, imagery may simultaneously activate the corresponding action. Despite this initial evidence, the automatic link between imagination and behavior in the context of more complex actions-including purchase behavior-is yet to be examined. As the integration of neuroscience and consumer research has proved fruitful in other domains (Yoon, Gutchess, Feinberg, \& Polk, 2006), the use of neuroimaging to test the automatic link between imagination and purchase behavior is likely to be a worthy endeavor.

\section{VARIABLES MODERATING THE EFFECTS OF IMAGERY}

The only limit of imagethinking is the unimaginable.

Mervyn Nicholson, 13 Ways of Looking at Images

\section{Vividness of the Product Information}

For imagery processing to occur, it is important that consumers be provided with sufficient knowledge and concrete cues (Pavio \& Csapo, 1973; Richardson, 1983; Wright \& Rip, 1980). Often, however, consumers are invited to imagine the product experience without being provided with such cues. For example, suppose you receive the following e-mail:

Earn up to 32,500 bonus points with American Express! Take a moment to consider all the rewards you can earn with Hilton HHonors points. Now, picture earning more points everyday for even greater travel rewards. American Express is providing you with a limited time opportunity to turn the best Hilton HHonors rewards you can imagine into a valuable reality!

Without a vivid description of the offered rewards, you would probably find it difficult to imagine yourself earning these rewards as suggested in the message. How would that influence the likelihood that you would enroll in the promoted program?

Research examining the use of vivid information as an imagery-eliciting strategy has employed various ways to manipulate vividness; these include presence versus absence of pictures (Keller \& Block, 1997; Kiseilius \& Sternthal, 1984), concrete versus abstract pictures (Babin \& Burns, 1997; Mitchell \& Olson, 1981), concrete versus abstract words (Robertson, 1987; Rook, 1987), narrative versus statistical information (Keller \& Block, 1997), and detailed product description versus expert ratings (Petrova \& Cialdini, 2005). Based on the premise that concrete words can stimulate greater generation of imagery (MacInnis \& Price, 1987; Pavio \& Csapo, 1973; Pavio \& Foth, 1970; Pavio, Yuille, \& Madigan, 1968; Richardson, 1980), research demonstrates that messages using concrete wording are more persuasive than those using abstract wording (Adaval \& Wyer, 1998; Robertson, 1987; Rook, 1987). Studies manipulating the vividness of the information through the use of pictures further indicate the capacity of pictures to evoke imagery (Bugelski, 1983; Finke, 1980; Pavio, 1971; Shepard, 1967; Singer, 1978) and influence product evaluations (Childers \& Houston, 1984; Lutz \& Lutz, 1977, 1978; Macinnis \& Price, 1987; Mitchell, 1986).

The vividness of the product depiction has a special role in the effect of imagery appeals. Vivid product attributes have a disproportionate influence on product preferences when consumers pro- 
cess the product information using imagery (Keller \& McGill, 1994; McGill \& Anand, 1989). Moreover, because consumers are likely to base their purchase intentions on the ease with which they can imagine the product experience, asking consumers to imagine the product experience in the absence of vivid product information may not only be inefficient but may actually decrease the likelihood of purchasing the product (Petrova \& Cialdini, 2005). For example, when the photograph in a vacation ad was modified to resemble an abstract painting, incorporating imagery appeals in the ad decreased its persuasiveness in comparison to that of an ad that lacked such appeals. Similarly, when a restaurant was described with highly positive numerical expert ratings, asking individuals to process the information using their imagination decreased the likelihood of their purchasing the product. On the other hand, imagery appeals increased product choice when the abstract information was replaced with a vivid, imagery-evoking description (e.g., the dining room, with its old wooden floor and peach color walls, basks in a soft gentle light... the meat is so tender that you can feel it melt on your tongue).

Importantly, these effects were observed despite the fact that the vivid and the nonvivid product depictions were equally persuasive in the absence of imagery appeals (Petrova \& Cialdini, 2005). According to these findings, the type of processing strategy that consumers engage in determines whether vivid information is more persuasive than abstract, nonexperiential information. In fact, when individuals are motivated to process the information analytically and to make a logical decision, describing the product with vivid, imagery-evoking information decreased the likelihood of choosing the product (Petrova \& Cialdini, 2005). Yet, presenting a vivid product depiction is crucial when consumers are asked to imagine their future experience with the product. Without a vivid product depiction, imagery appeals may not only be ineffective, they can decrease the persuasiveness of the message.

\section{Cognitive Load}

In order for consumers to imagine their future experience with the product, they should not only be provided with the appropriate information; they should also have the cognitive capacity to do so. Because imagery is a resource-demanding process (MacInnis \& Price, 1987; McGill \& Anand, 1989; Unnava et al., 1996) allocating resources to another cognitive task may undermine its effects. For example, in a study by Shiv and Huber (2000), cognitive load was manipulated by asking participants to memorize a nine-digit number that prevented them from engaging in mental imagery. This diminished the otherwise observed shift in preferences between anticipated-satisfaction judgments and choice. Increased cognitive load may also result from considering factual information simultaneously with constructing the suggested mental image. For example, along with imagery-evoking information, product depictions are frequently accompanied by nonexperiential information such as numerical ratings, technical specifications, or attribute comparisons. A potential drawback of such an approach is that consumers may experience difficulty in simultaneously processing these two types of information. For instance, adding numerical expert ratings to a vivid product depiction undermined the effects of imagining instructions despite the fact that the numerical ratings enhanced product preferences when participants were processing the information analytically (Petrova \& Cialdini, 2005). In another study, adding statistical information to a story of success diminished the otherwise positive effect of the story on participants' expectations for their own success (Mandel, Petrova, \& Cialdini, 2006). Comparative information can have similar effects. For example, adding attribute comparison between the advertised brand and the competitor undermined brand preferences under imagery processing. This effect was observed 
despite the fact that the comparative information had a positive effect on brand attitudes when participants engaged in analytical processing (Thompson \& Hamilton, 2006).

According to these findings, when consumers engage in imagery, adding nonexperiential information will not only fail to increase the persuasiveness of the message but can undermine the effects of imagery appeals. That is, imagery instructions are likely to be effective only when the vivid information is the only information that the consumer considers. Further research is needed to examine the effects of cognitive load on imagery. This research would benefit from examining the impact of other factors that can undermine consumers' cognitive capacity to generate the suggested imagery (e.g., time pressure, distractions in the environment). Along with its practical implications, such research would provide better light into the cognitive processes involved in the effects of imagery on product preferences.

\section{Self-Relevant Versus Other-Relevant Imagery}

Engaging in imagery may have different effects on subsequent evaluations and behavior, according to whether consumers imagine themselves or another person. A number of studies demonstrate that visualization has stronger effects on one's intentions if it involves the self, rather than another person (Anderson, 1983; Bone \& Ellen, 1992; West, Huber, \& Min, 2004). For example, in a set of studies by Bone and Ellen (1992), participants heard a popcorn radio ad in which they were asked to imagine either themselves or an eccentric chemistry professor consuming the advertised product. Those who imagined themselves reported greater imagery generation, more positive attitudes toward the brand, and greater likelihood of purchasing the product than those who imagined another person (in this case, an eccentric chemistry professor). Research examining the effects of self- versus other-relevant imagery evoked by reading a narrative story about another person revealed consistent results. Reading about someone else's success increased participants' luxury brand preferences and expectations for their own success, but only when participants could easily imagine themselves in the story (Mandel, Petrova, \& Cialdini, 2006).

Neuroimaging research has further revealed that imagining the self and imagining another person are related to somewhat different brain activities. For example, participants in a study by Ruby and Decety (2001) were trained to imagine either themselves or another individual performing a series of actions. Both self-relevant and other-relevant imagery activated common clusters in the SMA, the precentral gyrus, and the precuneus. However, some differences in the activated areas when imagining oneself or another person were also observed. While imagining the self was specifically associated with increased activity in the left inferior parietal lobule and the left somatosensory cortex, imagining another person activated the right inferior parietal lobule, the posterior cingulate, and the fronto-polar cortex (Ruby \& Decety, 2001). The effects of self- versus other-relevant imagery have also been studied in the experience of pain. Both imagining oneself and imagining another individual in pain have been found to activate the neural network involved in pain processing, including the parietal operculum, ACC, and anterior insula (Jackson et al., 2005). However, imagining the self in pain resulted in higher pain ratings and involved the pain matrix more extensively in the secondary somatosensory cortex, the posterior part of the anterior cingulate cortex, and the insula proper.

These results suggest that consumers are more likely to purchase a product when they imagine themselves using the product rather than another person. However, there is a notable exception to this conclusion. Under some circumstances, instead of asking consumers to imagine themselves with the product, marketers would be better advised to ask consumers to imagine a broader audience. That is, when imagining their experience with a product, consumers usually rely on past 
experience with similar products. However, when it comes to novel, innovative products that allow consumers to do something they have never been able to do before (Robertson, 1971; Ulrich \& Eppinger, 2000), consumers could no longer rely on their own past experiences. In this case it is more effective to encourage more abstract imagery (e.g., imagine how a consumer can use this notepad to transfer handwritten notes to a digital file; Dahl \& Hoeffler, 2004). Although further research is needed to examine the processes involved when consumers imagine really new products, these findings suggest that under some conditions, other-relevant visualization may result in more positive evaluations of the product than self-relevant visualization.

\section{Process-Oriented Versus Outcome-Oriented Imagery}

Recent research distinguishes between process- versus outcome-based mental simulation (Escalas \& Luce 2003, 2004; Oettingen \& Mayer, 2002; Pham \& Taylor, 1999; Rivkin \& Taylor, 1999; Taylor, Rivkin, \& Armor, 1998). Process-focused imagery emphasizes the actions necessary to achieve an outcome. It encourages plan formation by creating a step-by-step story or narrative. Outcome-focused imagery, on the other hand, emphasizes the end of the story, such as the positive benefits of consuming the product. Escalas and Luce (2004) found different mechanisms involved in the two types of imagery. In outcome-focused imagery, individuals' sensitivity to argument strength increased when participants were explicitly asked to pay attention to the information in the ad. This finding is consistent with the elaboration likelihood model of persuasion (Chaiken \& Trope, 1999; Petty \& Cacioppo, 1986) and with the availability-valence paradigm (Kissielius \& Sternthal, 1984). However, Escalas and Luce found that under process-focused imagery, asking participants to pay attention to the ad decreased the participants' sensitivity to argument strength. This finding is consistent with the transportation and reduced counterarguing explanation of the effects of imagery (Escalas, 2004; Green \& Brock, 2000) as well as with the imagery accessibility account (Petrova \& Cialdini, 2005).

One variable that may influence whether individuals will engage in process- or outcome-focused imagery is the temporal distance of the imagined event. According to the construal level theory (Liberman \& Trope, 1998; Trope \& Liberman, 2000, 2003), the temporal distance of an event changes the way in which that event is mentally represented. When consumers think of near-future events, they tend to focus on concrete aspects such as the product feasibility. On the other hand, when making a decision about consequences in the distant future, consumers are more likely to think of abstract features of the product such as its desirability. It is possible, therefore, that consumers will be more likely to engage in process-oriented simulation when imagining a near future event and more likely to engage in outcome-oriented simulation when imagining a distant future event. If that is the case, marketers should be highlighting different features of the product depending on the temporal distance of the imagined event. Moreover, messages that are relevant to near future consumption and distant future consumption should be structured in a way that facilitates the type of mental simulation in which consumers are likely to engage. Marketers should also be aware that focusing on different features according to the temporal distance of an event can lead to inconsistency of preferences over time (Liberman \& Trope, 1998). That is, when considering a purchase in the distant future, consumers may choose the option that is more desirable. However, when the time for making the purchase approaches, consumers may shift their preferences toward the more feasible option. One way to prevent such shift in preferences is to engage consumers who consider a distant future purchase in process-oriented mental simulation and thus increase feasibility-related considerations. As a result, consumers will be more consistent in their preferences at the time of making the initial decision and the time of purchase (Zhao, Hoeffler, \& Zauberman, 2007). 


\section{Individual Differences}

Dispositional imagery vividness. Individuals' ability to generate vivid mental images has been shown to be a stable dispositional characteristic. Several scales exist to measure dispositional imagery abilities. For example, Betts's Questionnaire Upon Mental Imagery (QMI) assesses individual differences in imagery vividness in regard to visual, auditory, cutaneous, kinesthetic, gustatory, olfactory, and organic modalities (Betts, 1909; Sheenan, 1967). Another scale, the Vividness of Visual Imagery Questionnaire (VVIQ; Marks, 1973), assesses imagery abilities in regard to visual images only. Research using measures of imagery abilities has demonstrated the impact of dispositional imagery vividness on a variety of psychological processes; these include hypnotizability (Crawford, 1982), creativity (Shaw \& Belmore, 1982), and information processing (Hiscock, 1976; Marks, 1973; Pham, Meyvis, \& Zhou, 2001; Swann \& Miller, 1982).

The individual's ability to generate mental images can also influence the effect of imagining instructions. For example, individuals high in dispositional imagery vividness were better able to memorize a sentence when they were instructed to create a mental image of the situation in the sentence rather than repeat the sentence to themselves. For low imagers, however, both strategies were equally effective in memorizing the target sentences (Slee, 1978). Similarly, in a study by Bone and Ellen (1992), participants' imagery ability had an effect on (1) the reported vividness of the image of consuming the advertised brand and (2) the subjectively perceived ease of imagining experiencing the product. These two variables, in turn, had a significant impact on the attitudes toward the advertised brand. Differences in imagery abilities can even reverse the effects of imagery appeals. Consistent with the imagery accessibility account, imagery appeals enhanced attitudes and intentions toward purchasing the product for high imagers, whereas among low imagers, difficulties in creating the suggested mental image decreased subsequent product evaluations (Petrova \& Cialdini, 2005).

Internal focus. Because imagery involves processing information by generating an internal sensory representation of the perceived information, individuals who tend to focus on their internal representations and experiences are likely to be influenced by imagery processes to a greater extent. The tendency of individuals to pay attention to their internal experiences has been well documented as a stable dispositional variable (Fenigstein, Scheier, \& Buss, 1975). To measure the general tendency toward self-focused attention, Fenigstein et al. constructed the Self-Consciousness Scale, which has two factors: public self-consciousness and private self-consciousness. The public self-consciousness factor measures awareness of oneself as a social object; the private self-consciousness factor measures awareness of one's inner thoughts, feelings, and experiences. For example some of the items from the private self-consciousness scale include "I reflect about myself a lot" and "I'm generally attentive to my inner feelings."

Research using the private self-consciousness scale as a measure of dispositional internal focus has demonstrated stronger effects of imagery for individuals high in internal focus (Petrova \& Cialdini, 2005). However, more research is needed to examine the relationship between the effects of imagery and internal focus and to investigate other variables that can influence self-focused attention and consequently the effects of imagery appeals. For example, manipulations of internal focus through the use of a mirror have demonstrated effects similar to the effects of private self-consciousness (Carver \& Scheier, 1978). On the other hand, it has also been suggested that chronic differences in internal focus and situational manipulations may have different effects (Hull, Slone, Meteyer, \& Matthews, 2002). Thus, future research needs to examine the possible differential effects of dispositional and situationally manipulated internal focus in regard to imagery. Future 
research may also examine novel variables that may influence internal focus and consequently moderate the effects of imagery.

\section{CONCLUSIONS AND DIRECTIONS FOR FUTURE RESEARCH}

Imagination is more important than knowledge.

\section{Albert Einstein}

We reviewed evidence for a strategy of influencing consumers that, rather than providing logical arguments, draws consumers into an imagined reality that includes the product. Although imagery has long been recognized and used as a strategy of influence, consumer researchers have only recently started to systematically investigate the psychological mechanisms underlying its effects. The research discussed in this chapter provides important insights into the powerful effects of visualization on consumers' preferences and behavior. Moreover, it suggests processes that are conceptually different from the psychological mechanisms traditionally studied by influence and persuasion researchers. Yet, more research is needed to uncover the processes through which imagery influences consumers and the conditions under which such effects occur. In the following sections we examine some possibilities for research in these directions.

\section{What Are the Mechanisms Through Which Imagery Influences Consumers?}

We reviewed several processes that are suggested to underlie the effects of imagery. As proposed by the availability-valence hypothesis (Kissielius \& Sternthal, 1984), when asked to imagine their experience with the product, consumers are more likely to elaborate on the product information as well as to bring to mind relevant positive or negative product information. Depending on the favorability of the information made accessible, imagery can increase or decrease product evaluations. The availability-valence hypothesis is consistent with many theories of consumer judgment according to which consumers make judgments by examining the implications of each piece of product information that they have available.

More recent research, however, proposes an alternative view. For example, the transportation account suggests that when consumers imagine their experience with the product, they process the information holistically. Consequently, they are less likely to be influenced by the favorability of the presented information (Adaval \& Wyer, 1998) and the strength of the presented arguments (Escalas, 2004). The imagery accessibility account (Petrova \& Cialdini, 2005) further suggests that imagery creates a readily available mental image of the consumption experience. Instead of examining the favorability of the product information, consumers may base their decisions on the ease with which a mental image of having the product comes to mind. Imagery also has an effect on consumers' affective responses to the ad and the product. And finally, there might be more direct effects of mental images through an automatic link between perception and behavior.

Future research should shed more light on the processes through which imagery influences consumers' judgments and behavior. Future research should also examine how these processes interact and what are the direct outcomes that each of the processes is likely to influence. For example, the emotional response to the message and the valence of the accessible information may directly influence brand attitudes (Bone \& Ellen, 1992). On the other hand, if the effects of imagery are mediated by (a) the increased accessibility of the consumption images or (b) a direct automatic link between imagination and behavior, then imagery should have a more direct effect on purchase intentions (Gregory et al., 1982; Schlosser, 2003). Some evidence for such independent effects of imagery on 
behavioral intentions comes from research by Schlosser (2003), in which participants viewed a Web site that had either passive or interactive information about Kodak cameras. While product interactivity increased brand attitudes among participants instructed to have fun and look at whatever they considered interesting, participants who were instructed to search the Web site with the goal of finding something specific held less favorable brand attitudes when looking at the interactive site than after looking at the passive site. However, regardless of whether participants were searching for specific information or browsing the Web site for fun, they had stronger purchase intentions after viewing the interactive Web site. Imagery, evoked by object interactivity, had a positive effect on intentions even when it resulted in more negative attitudes. These findings suggest that, depending on the cognitive processes taking place, imagery may influence brand attitudes or have a direct effect on intentions.

Future research should examine the circumstances under which the different processes are likely to take place. A promising direction for such research is the distinction between process- versus outcome-based mental simulation (Escalas \& Luce, 2003, 2004) which suggests that a different set of psychological processes will be activated according to whether consumers imagine the process or the outcome of using the product.

Another fruitful direction for research is to examine the role of imagery in other processes through which consumers form their preferences. Incorporating research on imagery in other domains may prove useful in understanding phenomena such as narrative persuasion, media effects, and social comparison processes. For instance, research on the effects of social comparison (Festinger, 1954) established that individuals tend to evaluate their own opinions and abilities by comparing themselves to others (Lockwood, 2002; Mills, Polivy, Herman, \& Tiggemann, 2002; Mussweiler, 2003; Richins, 1991). This research has further revealed that social comparison can result in contrast effects (in which individuals alter their judgments and expectations in a direction opposite of the comparison target) or assimilation effects (in which individuals changed their judgments in a direction toward the comparison target). Little is known, however, about the cognitive processes underlying these effects (Mussweiler, 2003). Taking the role of imagery into account can bring valuable insights in this regard. When exposed to a comparison target, individuals may spontaneously attempt to imagine themselves in the same position. To the extent that they can easily imagine themselves in the place of the comparison target, an assimilation effect is likely to occur. On the other hand, when individuals experience difficulty imagining themselves in the place of the comparison target, a contrast effect is likely to occur. Evidence for this possibility was provided in a series of studies (Mandel, Petrova, \& Cialdini, 2006) in which business students increased their expectations for success and their luxury brand preferences when they compared themselves to a successful business student. However, they found it difficult to imagine themselves in the place of a successful biology major, and trying to do so reduced their expectations for success in the future.

\section{When Does Imagery Influence Consumers' Judgments?}

Although imagery processing can have powerful effects on product evaluations, our review of the existing literature reveals that such effects are likely to occur only under specific circumstances. We reviewed several factors that can undermine the effects of imagery: (a) individual differences that reduce imagery vividness and internal focus, (b) low vividness of the product information, (c) high cognitive load, and (d) low relevance of the imagined scenario to the self. Moreover, we reviewed evidence suggesting that when individuals experience difficulty generating the suggested mental image as a result of any of these factors, imagery appeals can not only be ineffective but can decrease the likelihood of purchasing the product. When implementing imagery appeals as 
a strategy of persuasion, therefore, marketers should be aware of the possibility that under some circumstances, encouraging imagining may decrease the persuasiveness of the ad.

Future research is needed to examine the circumstances under which the experience of ease or difficulty in imagining the product experience is likely to influence consumers' judgments. One variable that has been demonstrated to moderate these effects is the extent to which consumers are likely to focus on their internal experiences. For example, although imagery fluency had an impact on product choice for participants high in private self-consciousness, those low in private self-consciousness were equally likely to choose the product regardless of whether it was easy or difficult for them to imagine the product experience (Petrova \& Cialdini, 2005). Future research should examine the potential moderating role of other variables related to individuals' focus on their subjective experiences. For example, Pacini and Epstein (1999) identified stable dispositional differences in the extent to which individuals process information experientially or analytically. Because individuals who tend to process information experientially are sensitive to their intuitions and subjective experiences (Danziger, Moran, \& Rafaely, 2006; Pacini \& Epstein, 1999), it seems likely that these would be the consumers who would be most influenced by imagery evoking information. The specific effects of individuals' tendency toward an experiential or analytical style of processing, as well as the effects of situational factors that prime one or the other processing style, are yet to be examined.

It is also important for future research to examine the conditions under which the experience of ease or difficulty of imagining the product experience is likely to be perceived as diagnostic (Tybout, Sternthal, Malaviya, Bakamitsos, \& Park, 2005; Zhao, Hoeffler, \& Dahl, 2007). For example, consumers may not be influenced by the experience of difficulty imagining the product experience for product categories that are generally difficult to imagine. The consumers' interpretation of this experience influences whether the experience of fluency will increase or decrease the likelihood of purchasing the product (Brinol, Petty, \& Tormala, 2006; Unkelbach, 2006). Thus, there may be circumstances in which the experience of ease in imagining the product experience will have a negative effect on judgments.

It will also be fruitful for future research to examine the effects of imagery for different types of products. The existing findings converge across a variety of products, such as automobiles (Burns, Biswas, \& Babin, 1993; McGill \& Anand, 1989), beer (Rossiter \& Percy, 1978), apartments (Keller \& McGill, 1994; McGill \& Anand, 1989), restaurants (Petrova \& Cialdini, 2005), cameras (Schlosser, 2003), and vacations (Adval \& Wyer, 1998; Krisnamurty \& Sujan, 1999; Petrova \& Cialdini, 2005). However, all of these product categories have an experiential component, and the product use has been associated with positive affect. Although there is evidence for the effects of imagination on products with a greater utilitarian component, such as computers (Zhao, Hoeffler, \& Dahl, 2007), further research is needed to examine possible differences in the effects of imagery on different types of products. For example, imagery may have a different effect with products associated with extraordinary experiences-such as skydiving, rock climbing, or river rafting-in which consumers are looking for something beyond their imagination and some of the value of the experience comes from its unpredictable nature (Abrahams, 1968; Arnould \& Price, 1993). Furthermore, research suggests that imagery appeals may have different effects on evaluations of new products, especially innovative products that define a novel product category. Because it is typically difficult for consumers to imagine the use of such products, marketers may need to use different ways to engage the consumers' imagery when introducing really new products (Dahl \& Hoeffler, 2004; Zhao, Hoeffler, \& Dahl, 2007).

As is the case with most persuasion research, the majority of the studies reviewed in this chapter examined the effects of imagery directly after the presentation of the message. There have been 
notable exceptions. For example, Gregory et al. (1982) suggested that imagining the product experience can impact purchase intentions even weeks later. Furthermore, as research by Anderson (1983) demonstrates, repeatedly imagining a scenario can increase the likelihood of performing the imagined behavior. Nevertheless, future research can examine the temporal effects of imagery, especially regarding imagining consumption experiences. Future research should also examine how imagery-processed information influences not only consumers' judgments and purchases but also other aspects of the consumption process, such as decision confidence (Thompson, Hamilton, \& Petrova, 2007), satisfaction (MacInnis \& Price, 1990; Shiv \& Huber, 2000), and word-of-mouth (Petrova, 2007).

\section{REFERENCES}

Abrahams, R. D. (1986). Ordinary and extraordinary experience. In V. W. Turner \& E. M. Bruner (Eds.), The anthropology of experience (pp. 45-73). Urbana: University of Illinois Press.

Adaval, R., \& Wyer, R. S. (1998). The role of narratives in consumer information processing. Journal of Consumer Psychology, 7(3), 207-245.

Anderson, C. A. (1983). Imagination and expectation: The effect of imagining behavioral scripts on personal intentions. Journal of Personality and Social Psychology, 45(2), 293-305.

Ansfield, M., \& Wegner, D. (1996). The feeling of doing. In P. M. Gollwitzer \& J. A. Bargh (Eds.), The psychology of action (pp. 482-506). New York: Guilford.

Arnould, E. J., \& Price, L. L. (1993). River magic: Extraordinary experience and the extended service encounter. Journal of Consumer Research, 20 (June), 24-45.

Babin, L. A., \& Burns, A. C. (1997). Effects of print ad pictures and copy containing instructions to imagine on mental imagery that mediates attitudes. Journal of Advertising, 26, 3.

Bargh, J. A., Chen, M., \& Burrows, L. (1996). Automaticity of social behavior: Direct effects of trait construct and stereotype activation on action. Journal of Personality and Social Psychology, 71(2), 230-244.

Bargh, J. A., Gollwitzer, P. M., Lee-Chai, A., Barndollar, K., \& Trörschel, R. (2001). The automated will: Nonconcious activation and pursuit of behavioral goals. Journal of Personality and Social Psychology, 81(6), 1014-1027.

Betts, G. H. (1909). The distribution and function of mental imagery. New York: Columbia University Press.

Bolls, P. D. (2002). I can hear you, but can I see you? The use of visual cognition during exposure to highimagery radio advertisements. Communication Research, 29(5), 537-563.

Bone, P. F., \& Ellen, P. S. (1992). The generation and consequences of communication-evoked imagery. Journal of Consumer Research, 19(1), 93-103.

Brinol, P., Petty, R., \& Tormala, Z. L. (2006). The meaning of subjective ease and its malleability. Psychological Science.

Bugelski, B. R. (1983). Imagery and the thought process. In A. Sheikh (Ed.), Imagery: Current Theory, Research and Application (pp. 72-95). New York: Wiley.

Burns, A. I., Biswas, A., \& Babin, L. L. (1993). The operation of mental imagery as a mediator of advertising effects. Journal of Advertising, 22(2), 71-85.

Cacioppo, J. T., Petty, R. E., \& Kao, C. F. (1984). The efficient assessment of need for cognition. Journal of Personality Assessment, 48 (June), 306-307.

Carroll, J. S. (1978). The effect of imagining an event on expectations for the event: An interpretation in terms of the availability heuristic. Journal of Experimental Social Psychology, 14, 88-96.

Chaiken, S., \& Trope, Y. (1999). Dual-process theories in social psychology. Guilford.

Chartrand, T. L., Maddux, W. W., Lakin, L. J. (2005). Beyond the perception-behavior link: the ubiquitous utility and motivational moderators of nonconscious mimicry. In R. R. Hassin, J. S. Uleman \& J. A. Bargh (Eds.), The New Unconscious (pp. 334-361). New York: Oxford Univiversity Press.

Childers, T. L., \& Houston, M. J. (1984). Conditions for a Picture-Superiority Effect on Consumer Memory. Journal of Consumer Research, 11(2), 643-654.

Childers, T. L., Houston, M. J., \& Heckler, S. H. (1985). Measurement of individual differences in visual versus verbal information processing. Journal of Consumer Research, 12(2), 125-134. 
Cialdini, R. B. (2001). Systematic opportunism: An approach to the study of tactical social influence. In P. J. Forgas \& K. D. Williams (Eds.), Social influence: direct and indirect processes. Philadelphia: Psychology Press.

Crawford, H. J. (1982). Hypnotizability, daydreams styles, imagery vividness and absorption: A multidimensional study. Journal of Personality and Social Psychology, 42(5), 915-926.

Dahl, D. W., \& Hoeffler, S. (2004). Visualizing the self: Exploring the potential benefits and drawbacks for new product evaluation. Journal of Product Innovation Management, 21 (July), 259-267.

Danziger, S., Moran, S., \& Rafley, V. (2006). The influence of ease of retrieval on judgment as a function of attention to subjective experience. Journal of Consumer Psychology, 16(2), 191-195.

Decety, J., Jeannerod, M., Germain, M., \& Pastene, J. (1991). Vegetative response during imagined movements is proportional to mental effort. Behavioral Brain Research, 42, 1-5.Deighton, J., R., D., \& McQueen, J. (1989). Using drama to persuade. Journal of Consumer Research, 1 6(December), 335-343.

Dijksterius, A. P., \& Bargh, J. A. (2001). The perception-behavior expressway: Automatic effects of social perception on social behavior. Advances in Experimental Social Psychology, 33, 1-40.

Dijksterius, A. P., \& Knippenberg, A. (1998). The relation between perception and behavior, or how to win a game of trivial pursuit. Journal of Personality and Social Psychology, 74(4), 865-877.

Ehrsson, H. H., Geyer, S., \& Naito, E. (2003). Imagery of voluntary movement of fingers, toes and tongue activates corresponding body-part-specific motor representations. Journal of Neurophysiology, 90, 3304-3316.

Epstein, S. (1994). Integration of the cognitive and the psychodynamic unconscious. American Psychologist, 49 (August), 709-724.

Escalas, J. E. (2004). Imagine yourself in the product. Journal of Advertising, (33), 2.

Escalas, J. E. (2007). Self-referencing and persuasion: Narrative transportation versus analytical elaboration. Journal of Consumer Research(March).

Escalas, J. E., \& Luce, M. F. (2003). Process versus outcome thought focus and advertising. Journal of Consumer Psychology, 13(3), 246-254.

Escalas, J. E., \& Luce, M. F. (2004). Understanding the effects of process-focused versus outcome-focused thought in response to advertising. Journal of Consumer Research, 31 (September), 274-285.

Fenigstein, A., Scheier, M. F., \& Buss, A. H. (1975). Public and private self-consciousness - assessment and theory. Journal of Consulting and Clinical Psychology, 43(4), 522-527.

Festinger, L. (1954). A theory of social comparison processes. Human Relations, 7, 117-140.

Finke, R. A. (1980). Levels of equivalence in imagery and perception. Psychological Review, 87, (March), $113-132$.

Fitzsimons, G. J., \& Morwitz, V. M. (1996). The effect of measuring intent on brand level purchase behavior. Journal of Consumer Research, 23, 1-11.

Garry, M., \& Polaschek, D. L. (2000). Imagination and memory. Current Directions in Psychological Scienc $e, 9,1$.

Gonzalves, B., Reber, P. J., Gitelman, D. R., Parrish, T. B., Mesulam, M. M., \& Paller, K. A. (2004). Neural evidence that vivid imagining can lead to false remembering. Psychological Science, (15), 10.

Goossens, C. (1994). Enactive Imagery: Information processing, emotional responses, and behavioral intentions. Journal of Mental Imagery, 18(3\&4), 119-150.

Goossens, C. (2000). Tourism information and pleasure motivation. Annals of Tourism Research, 27(2), 301-322.

Green, M. C., \& Brock, T. C. (2000). The role of transportation in the persuasiveness of public narratives. Journal of Personality and Social Psychology, 79, 701-721.

Greenwald, A. G., Carnot, C. G., Beach, R., \& Young, B. (1987). Increasing voting behavior by asking people if they expect to vote. Journal of Applied Psychology, 72, 315-318.

Gregory, L. W., Cialdini, R. B., \& Carpenter, K. M. (1982). Self-Relevant scenarios as mediators of likelihood estimates and compliance: Does imagining make it so? Journal of Personality and Social Psychology, 43(1), 89-99.

Grèzes, \& Decety. (2001). Functional anatomy of execution, mental simulation, observation and verb generation of actions: a meta-analysis. Hum. Brain Mapp, 12(1-19.).

Griffth, D. A., \& Chen, Q. (2004). The influence of virtual direct experience VDE on on-line ad message effectiveness. Journal of Advertising, 3 (Spring). 
Grigorovici, D. (2003). Persuasive effects of presence in immersive virtual environments. In F. R. Davide, G. (Ed.), Being there: Concepts, effects and measurements of user presence in synthetic environments (pp. 191-207). Amsterdam: IOS Press.

Hiscock, M. (1976). Effects of adjective imagery on recall from prose. Journal of General Psychology, 94(2), 295-299.

Houston, M., Childers, T. L., \& Heckler, S. E. (1987). Picture-word consistency and the elaborative processing of advertisements. Journal of Marketing Research, 24(4), 359-369.

Hull, J. G., Slone, L. B., Meteyer, K. B., \& Matthews, A. R. (2002). The nonconsciousness of self-consciousness. Journal of Personality and Social Psychology Review, 83(2), 406-424.

Jackson, P. L., Brunet, E., Meltzoff, A. N., \& Decety, J. (2006). Empathy examined through the neural mechanisms involved in imagining how I feel versus how you feel pain. Neuropsychologia, 44(5), 752.

James, W. (1980). Principles of psychology. New York: Holt.

Jeannerod, M. (1994). The representing brain: Neural correlates of motor intention and imagery. Behavioral and Brain Sciences, 17, 187-245.

Jeannerod, M. (1997). The cognitive neuroscience of action. Blackwell.

Keller, P. A., \& Block, L. G. (1997). Vividness effects: A resource-matching perspective. Journal of Consumer Psychology, (24), December.

Keller, P. A., \& McGill, A. L. (1994). Differences in the relative influence of product attributes under alternative processing conditions: Attribute importance versus attribute ease of imagebility. Journal of Consumer Psychology, 3(1), 29-49.

Kieras, D. (1978). Beyond pictures and words: Alternative information processing models for imagery effects in verbal memory. Psychological Bulletin, 85, 532-544.

Kisielius, J., \& Sternthal, B. (1984). Detecting and explaining vividness effects in attitudinal judgments. Journal of Marketing Research, 21 (February), 54-64.

Kisielius, J., \& Sternthal, B. (1986). Examining the vividness controversy: An availability-valence interpretation. Journal of Consumer Research, 12, 418-431.

Krishnamurthy, P., \& Sujan, M. (1999). Retrospection versus anticipation: The role of the ad under retrospective and anticipatory self-referencing. Journal of Consumer Research, 26(June), 55-69.

Lee, A. Y., \& Labroo, A. A. (2004). The effect of conceptual and perceptual fluency on Brand Evaluation. Journal of Marketing Research, 41 (May), 151-165.

Levav, J., \& Fitzsimons, G. (2006). When questions change behavior: The role of ease of representation. Psychological Science, 17(3), 3.

Li, H., Daugherty, T., \& Biocca, F. (2002). Impact of 3-D advertising on product knowledge, brand attitude, and purchase intention: The mediating role of presence. Journal of Advertising, 31(3), 43-75.

Liberman, N., \& Trope, Y. (1998). The role of feasibility and desirability considerations in near and distant future decisions: A test of temporal construal theory. Journal of Personality and Social Psychology, 75(1), $5-18$.

Lockwood, P. (2002). Could it happen to you? Predicting the impact of downward comparisons on the self. Journal of Personality and Social Psychology, 82(3), 343-358.

Lord, C. G. (1980). Schemas and images as memory aids: Two modes of processing social information. Journal of Personality and Social Psychology, 38(2), 257-269.

Lutz, K., \& Lutz, R. (1977). Effects of interactive imagery on learning: Application to advertising. Journal of Applied Psychology, 62(4), 493-498.

Lutz, K., \& Lutz, R. (1978). Imagery-eliciting strategies: Review and implications of research. In H. K. Hunt (Ed.), Advances in consumer research (Vol. 5, pp. 611-620). Ann Arbor, MI: Association for Consumer Research.

MacInnis, D., \& Price, L. (1987). The role of imagery in information processing: Review and extensions. Journal of Consumer Research, 13(March), 473-491.

MacInnis, D., \& Price, L. (1990). An exploratory study of the effects of imagery processing and consumer experience on expectations and satisfaction. In R. Holman \& M. Solomon (Eds.), Advances in consumer research (pp. 41-47). Provo, UT: Association for Consumer Research.

MacInnis, D. J., Shapiro, S., \& Mani, G. (1999). Enhancing brand awareness through brand symbols. Advances in Consumer Research, 26, 601-608.

Mandel, N., Petrova, P. K., \& Cialdini, R. B. (2006). Images of success and the preference for luxury brands. Journal of Consumer Psychology, 16 (January), 57-69. 
Mani, G., \& MacInnis, D. J. (2001). Imagery instructions, imagery processes and visual persuasion. In R. Batra \& L. L. Scott (Eds.), Advertising and consumer psychology.

Marks, D. F. (1973). Visual imagery differences in the recall of pictures. British Journal of Psychology, 64(1), $17-24$.

McGill, A. L., \& Anand, P. (1989). The effect of vivid attributes on the evaluation of alternatives: The role of differential attention and cognitive elaboration. Journal of Consumer Research, 16(September), 188-196.

Menon, G., \& Raghubir, P. (2003). Ease-of-retrieval as an automatic input in judgments: A mere-accessibility framework? Journal of Consumer Research, 30, 230-243.

Michelon, P., Vettel, J. M., \& Zacks, J. M. (2005). Lateral somatotopic organization during imagined and prepared movements. J. Neurophysiol.

Mick, D. G. (1987). Toward a semiotic of advertising story grammars. In J. Umiker-Sebeok (Ed.), Marketing and semioyics: New directions in the study of signs for sale (pp. 249-278). Berlin: Walter de Gruyter.

Mills, J. S., Polivy, J. C., Herman, P., \& Tiggemann, M. (2002). Effects of exposure to thin media images: Evidence of self-enhancement among restrained eaters. Personality and Social Psychology Bulletin, 28 (December), 1687-1699.

Mitchell, A. A. (1986). The effect of verbal and visual components of advertisements on brand attitudes and attitude toward the advertisement. Journal of Consumer Research, 13(1), 12-24.

Mitchell, A. A., \& Olson, J. C. (1981). Are product attribute beliefs the only mediator of advertising effects on brand attitude. Journal of Marketing Research, 18(3), 318-332.

Morwitz, V. G., \& Fitzsimons, G. J. (2004). The mere-measurement effect: Why does measuring intentions change actual behavior? Journal of Consumer Psychology(14), 64-73.

Mussweiler, T. (2003). Comparison processes in social judgment: Mechanisms and consequences. Psychological Review, 110, 472-489.

Nicholson, M. (2003). 13 ways of looking at images: The logic of visualization in literature and society. Beverly Hills, CA: Red Heifer Press.

Oettingen, G., \& Mayer, D. (2002). The motivating function of thinking about the future: Expectations versus fantasies. Journal of Personality and Social Psychology, 83(5), 1198-1212.

Olliver, R. L., Thomas, S. R., \& Mitchell, D. J. (1993). Imagining and analyzing in response to new product advertising. Journal of Advertising, 22(4), 35-50.

Pacini, R., \& Epstein, S. (1999). The relation of rational and experiential information processing styles to personality, basic beliefs, and the ratio-bias phenomenon. Journal of Personality and Social Psychology, 76(6), 972-987.

Paus, T., Petrides, M., Evans, A. C., \& Myer, E. (1993). Role of human anterior cingaluate cortex in the control of oculomotor, manual and speech responses: A positron tomography study. Journal of Neurophysiology, 70, 453-469.

Pavio, A. (1971). Imagery and verbal processes. New York: Holt, Rinehart, \& Winston.

Pavio, A., \& Csapo, K. (1973). Picture superiority in free recall: Imagery or dual coding. Cognitive Psychology, $5,176-206$

Pavio, A., \& Foth, D. (1970). Imaginal and verbal mediators and noun concreteness in paired associate learning: The elusive interaction. Journal of Verbal Learning and Behavior, 9, 384-390.

Pavio, A., Yuille, C., J., \& Madigan, S. A. (1968). Concreteness, imagery and meaningfulness values for 925 nouns. Journal of Experimental Psychology, 76, 1-25.

Petrova, P. K., \& Cialdini, R. B. (2005). Fluency of consumption imagery and the backfire effects of imagery appeals. Journal of Consumer Research, 32 (December), 442-452.

Petrova, P. K. (2007). Effects of communicating information on consumers' judgments. Working paper.

Petty, R. E., \& Cacioppo, J.T. (1986). Communication and persuasion: Central and peripheral routes to attitude change. New York: Springer-Verlag.

Pham, L., \& Taylor, S. (1999). From thought to action: Effects of process-versus outcome-based mental simulations on performance. Personality and Social Psychology Bulletin, 25 (February), 250-260.

Pham, M. T., Meyvis, T., \& Zhou, R. (2001). Beyond the obvious: Chronic vividness of imagery and the use of information in decision-making. Organizational Behavior and Human Decision Processes, 84(2), 226-253.

Pulvermuller, F., Härl, M., \& Hummel, F. (2001). Walking or talking? Behavioral and neuropsychological correlates of action verb processing. Brain and Language, 78, 143-198. 
Puto, C., \& Wells, W. (1984). Informational and transformational advertising: The differential effects of time. In T. C. Kinnear (Ed.), Advances in Consumer Research (11 ed., pp. 572-576). Provo, UT: Association for Consumer Research.

Richardson, A. (1969). Mental imagery. London: Routledge and Kegan Paul.

Richardson, A. (1983). Imagery: Definition and types. In A. A. Sheikh (Ed.), Imagery: current theory, research, and application (pp. 3-42). New York:Wiley.

Richins, M. (1991). Social comparison and the idealized images of advertising. Journal of Consumer Research, 19(June), 71-83.

Rivkin, I. D., \& Taylor, S. E. (1999). The effects of mental simulation on coping with controllable stressful events. Personality and Social Psychology Bulletin, 25(12), 1451-1462.

Rizzolatti, G., \& Arbib, M. A. (1998). Language within our grasp. Trends in Neuroscience, 21, 188-194.

Robertson, K. R. (1987). Recall and recognition effects of brand name imagery. Psychology and Marketing, 4, $3-15$.

Robertson, T. S. (1971). Innovative behavior and communication. New York: Holt.

Rook, D. W. (1987). The buying impulse, Journal of Consumer Research. 14(2), 189-199.

Rossiter, J., \& Percy, L. (1978). Visual imaging ability as a mediator of advertising response. In H. K. Hunt (Ed.), Advances in consumer research (Vol. 5, pp. 621-629). Ann Arbor, MI: Association for Consumer Research.

Ruby, P., \& Decety, J. (2001). Effect of subjective perspective taking during simulation of action: a PET investigation of agency. Nat. Neurosci, 4, 546-550.

Scheier, M., \& Carver, C. (1978). Self-focusing effects of dispositional self-consciousness, mirror presence, and audience presence. Journal-of-Personality-and-Social-Psychology, 36(3), 324-332.

Schlosser, A. E. (2003). Experiencing products in a virtual world: The role of goals and imagery in influencing attitudes versus intentions. Journal of Consumer Research, 30(September), 184-196.

Schlosser, A. E. (2006). Learning through virtual product experience: The role of imagery on true versus false memories. Journal of Consumer Research, forthcoming.

Schwarz, N. (1998). Accessible content and accessibility experiences: The interplay of declarative and experiential information in judgment. Journal of Personality and Social Psychology Review, 2(2), 87-99.

Schwarz, N. (2004). Metacognitive experiences in consumer judgment and decision making. Journal of Consumer Psychology, 14(4), 332-348.

Segal, S. J., \& Fusella, V. (1970). Influence of imaged pictures and sounds on detection of visual and auditory signals. Journal of Experimental Psychology, 83(March), 458-464.

Shaw, G. A., \& Belmore, S. M. (1982). The relationship between imagery and creativity. Imagination, Cognition and Personality, 2(2), 115-123.

Shepard, R. N. (1967). Recognition memory for words, sentences, and pictures. Journal of Verbal Learning and Verbal Behavior, 6, 156-163.

Sherman, S., Cialdini, R. B., Schwartzman, D. F., \& Reynolds, K. D. (1985). Imagining can heighten or lower the perceived likelihood of contracting a disease: The mediating effect of ease of imagery. Personality and Social Psychology Bulletin, 11, 118-127.

Shiv, B., \& Huber, J. (2000). The impact of anticipating satisfaction on consumer choice. Journal of Consumer Research, 27, 202-216.

Singer, J. (1978). Experimental studies of daydreaming and the stream of thought. In K. Pope \& J. Singer (Eds.), The Stream of Conciousness: Scientific Investigations into the Flow of Human Experience. New York: Plenum.

Singer, T., Seymour, B., O’Doherty, J., Kaube, H., Dolan, R. J., \& Frith, C. D. (2004). Empathy for pain involves the affective but not sensory components of pain. Science, 303, 1157-1161.

Slee, J. (1978). The consistency of different manipulations of visual imagery: A methodological study. Australian Journal of Psychology, (30), 7-20.

Stern, B. B. (1994). Classical and vignette television advertising dramas: Structural models, formal analysis, and consumer effects. Journal of Consumer Research, 20(4), 601-615.

Strack, F., Schwarz, N., \& Gschneidinger, E. (1985). Happiness and reminiscing: The role of time perspective, mood, and mode of thinking. Journal of Personality and Social Psychology, 49, 1460-1469.

Swann, W. B., \& Miller, L. C. (1982). Why never forgetting a face maters: Visual imagery and social memory. Journal of Personality and Social Psychology, 43(3), 457-480. 
Taylor, Rivkin, I., \& Armor, D. (1998). Harnessing the imagination: Mental simulation, self-regulation and coping. American Psychologist, 53(April), 429-439.

Thompson, D. V., \& Hamilton, R. W.. (2006). The effects of information processing mode on consumers' responses to comparative advertising. Journal of Consumer Research, 32(March), 530-540.

Thomson, D. V., Hamilton, R. W., \& Petrova, P. K. (2007). Process vs. outcome oriented mental simulation and choice difficulty, working paper.

Trope, Y., \& Liberman, N. (2000). Temporal construal and time-dependent changes in preference. Journal of Personality and Social Psychology, 79(6), 876-889.

Tybout, A. M., Sternthal, B., Malaviya, P., Bakamitsos, G. A., \& Park, S. (2005). Information accessibility as a moderator of judgments. Journal of Consumer Research, 32(June), 76-85.

Ulrich, K. T., \& Eppinger, S. D. (2000). Product design and development. Toronto, Canada: McGraw-Hill Higher Education.

Unkelbach, C. (2006). The learned interpretation of cognitive fluency. Psychological Science, 17(4), 339-345.

Unnava, R. H., Agarwal, S., \& Haugtvedt, C. P. (1996). Interactive effects of presentation modality and message-generated imagery on recall of advertising information. Journal of Consumer Research, 23(June), 1996.

Wänke, M., Bohner, G., \& Jurkowitsch, A. (1997). There are many reasons to drive a BMW: Does imagined ease of argument generation influence attitudes? Journal of Consumer Research, 24, (170-177.).

Wegner, D. M. (1994). Ironic processes of mental control. Psychological review, 101, (34-52).

West, P. M., Huber, J., \& Min, K. S. (2004). Altering experienced utility: The impact of story writing and selfreferencing on preferences. Journal of Consumer Research, 31 (December), 623-630.

Wright, P., \& Rip, P. D. (1980). Product Class Advertising Effects on 1St-Time Buyers Decision Strategies. Journal of Consumer Research, 7(2), 176-188.

Yoon, C., Gutchess, A. H., Feinberg, F., \& Polk, T. A. (2006). A functional magnetic resonance imaging study of neural dissociations between brand and person judgments. Journal of Consumer Research, 33(1), 31-40.

Zhao, M., Hoeffler, S., \& Dahl, D. (2007). Visualization and new product evaluation: The role of memory-and imagination-focused visualization. Advances in consumer research: Gavan J Fitzsimons and Vicki G. Morwitz, forthcoming.

Zhao, M., Hoeffler, S., \& Zauberman, G. (2007). Mental simulation and preference consistency over Time: The role of process- versus outcome-focused thoughts. Journal of Marketing Research, forthcoming. 
